BLS 32, No 1 2006. DOI: http://dx.doi.org/10.3765/bls.v32i1.3441 (published by the Berkeley Linguistics Society and the Linguistic Society of America)

\title{
An Analysis of the Use of Cognitive Verbs in American English Conversation
}

\author{
SUSAN BUESCHER ${ }^{1}$ \\ University of New Mexico
}

\section{Introduction}

This paper presents an analysis of the interactive functions of the frequent collocations I know, I think, and I guess, all of which involve a first person singular subject and a present tense verb of cognition and are used by participants to negotiate the floor during conversation. Previous studies have demonstrated that these collocations exhibit a high degree of fusion, are syntactically independent, and also have specific discourse functions as epistemic devices (cf. Thompson 2002; Scheibman 2000; Thompson and Mulac 1991a,b; Kärkkäinen 2003). However, little attention has been given to determining the different interactional roles played by these three collocations. Although all of the collocations discussed here involve verbs from the same semantic class that can occur in similar syntactic frames, the actual usage patterns of the collocations within conversation are very different. By combining a quantitative analysis of the characteristics of each collocation in regards to prosody and placement within a speaker turn with a qualitative analysis of the ways in which the collocations function within discourse contexts, this work seeks to show that there are concrete differences in the interactive functions of the collocations I know, I think, and I guess. Furthermore, it is proposed that the functional differences of the collocations are a direct result of the ways in which speakers have adapted certain collocations to meet their interactional needs during talk-in-interaction.

The layout of this paper is as follows: in the next section I discuss the previous research on cognitive verb collocations; in section two I briefly describe the corpus and outline the methodology; in section three I discuss intonation units and their theoretical framework; in section four I provide an analysis of each of the collocations and examine their varying roles as interactive devices in discourse; and finally, I conclude with an explanation of how these results provide evidence of the ways in which speakers manipulate language structure in order to meet

\footnotetext{
${ }^{1}$ I would like to thank Catherine Travis for her insightful comments and suggestions on this analysis.
} 
Susan Buescher

their interactional needs.

\section{Corpus-Based Research on Cognitive Verbs}

Recent studies based on corpora of naturally occurring discourse have shown that the high-frequency members of the class of cognitive verbs behave differently from low-frequency members and that frequent co-occurrence in certain grammatical constructions (such as with first person singular subjects) can lead to the development of collocations with special pragmatic functions.

In their work on verbs and subjects that occurred with 'that-less' complements, Thompson and Mulac (1991a,b) found that I think and I guess are the most frequent collocations to occur without the complementizer that, accounting for $65 \%$ of the 1287 instances in their data. They propose that these highly frequent complement-taking predicates have been reanalyzed by speakers as epistemic parentheticals, which are syntactically free to occur in various positions. The frequent use of these constructions as epistemic parentheticals illustrates how they have grammaticized from clausal heads to independent elements within discourse.

Related to this, but from a slightly different perspective, Diessel and Tomasello (2001) examined children's acquisition of complement clauses and found that when children use the verbs think, guess, bet, mean, and know in a main clause frame, the clause does not actually express a full proposition and instead functions as an epistemic parenthetical. They propose that this is evidence that the formulaic use of mental verbs such as think, know, and remember is acquired prior to the use of these verbs as performative complement-taking verbs.

Phonological reduction also commonly occurs within frequent collocations. Scheibman (2000) demonstrates that the most reduced variants of the auxiliary don't occur in the highly frequent constructions I don't know and I don't think, which she presents as evidence that these constructions behave more like phonologically fused words that are stored as single units. Furthermore, she notes that these single chunks have pragmatic roles in conversation, namely those of epistemic and face-saving devices, and are repeatedly used within specialized discourse environments.

The importance of examining discourse environments as a sign of function is acknowledged by Tao $(2001,2003)$, who presents analyses of the verbs remember and forget and suggests that despite their semantic similarities, in actual language use they have very different distributions and discourse functions. While forget is used almost exclusively with first person subjects, it frequently occurs in past tense constructions, unlike remember, which occurs almost exclusively in the present tense. Tao argues that this restricted range of use of remember is evidence that it primarily functions as a metalinguistic device that focuses on the interaction between the participants. He also proposes that the difference in the distribution of these two verbs is directly related to the degree of grammaticization of the constructions in which they occur.

Along similar lines, but by also including the effect of interaction, Kärkkäinen (2003) discusses the role of $I$ think as a stance marker and finds that the colloca- 


\section{The Use of Cognitive Verbs in American English}

tion occurs most often at the beginning or the middle of a turn, and not at the end. She proposes that having a position near the beginning of the multi-clause turn allows the collocation to have scope over a larger sequence of discourse. Furthermore, she notes that $I$ think is not often prosodically independent. When it does occur in its own intonation unit, she proposes that it has a specialized discourse role and is involved in the online planning of utterances, often cooccurring with hesitation devices and pauses.

Finally, Travis (in press) presents an analysis of a set of cognitive verbs in Spanish conversation. She finds that three individual verbs, saber 'to know', creer 'to believe', and pensar 'to think', account for $77 \%$ of the data, and that these three verbs occur most frequently in the specific constructions yo no sé 'I don't know', yo creo 'I believe', yo pienso 'I think', and yo pensé 'I thought'. She found that the most frequent verbs favored the use of expressed subjects, but did not favor the use of complement clauses, demonstrating that the cognitive verbs do not form a homogenous class; certain members of the class exhibit a higher degree of grammaticization and subjectification than others and for this reason have developed specific pragmatic functions within discourse.

These studies examine the functional effect of frequency on language structure and demonstrate that although the cognitive verbs may be categorized into a single verb class based on similarities in their semantics and syntactic frames, certain members are more specialized than others. Evidence of specialization is obtained through an examination of frequent collocations, specifically in terms of the phonological reduction within the collocations, and the freedom from syntactic constraints. The present work acknowledges the importance of syntactic and phonetic characteristics of collocations, but seeks to add to this field by now examining the specific prosodic characteristics of these collocations, as well as their placement within speaker turns, in order to ultimately determine and clarify the different interactional roles of the collocations I know, I think, and I guess.

\section{Data and Methodology}

The data for this study have been taken from the Santa Barbara Corpus of Spoken American English (cf. Du Bois et al. 2000, 2003, 2004), which has been transcribed following the transcription conventions developed by $\mathrm{Du}$ Bois et al. (1993). The corpus contains data from 38 naturally occurring spontaneous conversations between family and friends, as well as data from 8 informal meetings, lectures, and discussion groups. There are approximately 200,000 words in the corpus, representing a total of 57 hours of speech. The speakers who contributed to the corpus were between 17 and 90 years of age and were from various locations in the U.S.

The six most frequent verbs of cognition to occur in the corpus are presented

in Table 1. As can be observed, the two verbs know and think together account for $90 \%$ of the uses of cognitive verbs in the corpus. 
Susan Buescher

Table 1. Frequency of the cognitive verbs in the corpus

\begin{tabular}{|c|c|c|c|}
\hline verb & number & $\%$ & \\
\hline know & 1889 & 617 & \\
\hline think & 898 & 29 & \\
\hline remember & 111 & 3 & \\
\hline guess & 105 & 3 & \\
\hline believe & 63 & 2 & \\
\hline wonder & 47 & 2 & \\
\hline Total & 3113 & 100 & \\
\hline
\end{tabular}

Although these verbs are semantically similar, they each tend to be used a little differently in spoken discourse. Table 2 displays the most frequent collocations in which these six verbs occur.

Table 2. Most frequent cognitive verb collocations

\begin{tabular}{|c|c|c|c|c|}
\hline verb & collocation & \# of tokens & $\%$ of tokens & \\
\hline \multirow[t]{4}{*}{ know } & you know & 1154 & 61 & \multirow{4}{*}{$-83 \%$} \\
\hline & I don't know & 238 & 13 & \\
\hline & I know & 167 & 9 & \\
\hline & other & 330 & 17 & \\
\hline \multirow[t]{3}{*}{ think } & I think & 365 & 41 & \multirow{3}{*}{$-56 \%$} \\
\hline & I thought & 134 & 15 & \\
\hline & other & 399 & 44 & \\
\hline \multirow[t]{3}{*}{ remember } & I remember & 34 & 31 & \multirow[t]{3}{*}{$50 \%$} \\
\hline & Remember! (imperative) & 21 & 19 & \\
\hline & other & 56 & 50 & \\
\hline \multirow[t]{2}{*}{ guess } & I guess & 100 & 95 & \multirow{2}{*}{$-100 \%$} \\
\hline & guess what & 5 & 5 & \\
\hline \multirow[t]{2}{*}{ believe } & I can't believe & 10 & 16 & \\
\hline & other & 53 & 84 & \\
\hline \multirow[t]{2}{*}{ wonder } & I wonder & 28 & 60 & \\
\hline & other & 19 & 40 & \\
\hline Total & & 3113 & & \\
\hline
\end{tabular}

As can be seen in Table 2, the three cognitive verb collocations involving first person singular subjects, with affirmative, present tense verbs, and that also occur 


\section{The Use of Cognitive Verbs in American English}

at least 100 times in the corpus are the collocations I know, I think, and I guess. As these three collocations have also often been grouped together as 'epistemic devices', I know, I think, and I guess are especially interesting to compare. The rest of this paper will examine in more detail the different interactive roles of these three collocations by focusing on their prosodic characteristics, as well as their placement within speaker turns. Before turning to this discussion, however, I will first review the theoretical framework behind intonation units.

\section{Intonation Units}

Central to the analysis presented in this paper is the notion of the Intonation Unit (IU), which as described by Chafe (1994:60) is a functionally relevant segment of spoken discourse marked and bounded by several prosodic cues, such as pausing, a pattern of acceleration-deceleration, an overall decline in pitch level, a falling pitch contour at the end, and a change in voice quality. Because spoken discourse is not a continuous flow of sound, but tends to be produced in spurts, it easily lends itself to a division into intonation units.

IUs have several different types of pitch contours, which have different functions within discourse. There are four specific types of IUs described by Du Bois et al. (1993). IUs with final contours are marked by a decrease in pitch; IUs with continuing contours are marked by a rise in pitch; IUs with appealing contours are marked by a high rise in pitch, while truncated IUs have incomplete or unfinished contours. Functionally, a final contour is more likely to be used to mark the end of a turn-taking sequence; a continuing contour usually occurs within a single turn and indicates that the speaker has something more to say; and an appealing contour is likely to be used to engage another participant and elicit a response (Du Bois et al. 1993).

IUs can also be classified according to their lexical content. Chafe (1994) has proposed the following three types of IUs: regulatory IUs, which are used to regulate the interactional flow of discourse and frequently correspond to discourse markers; substantive IUs, which express informational substance and tend to have more words and more complex syntax, often corresponding to complete clauses; and finally, fragmented IUs, which are truncated or unfinished IUs.

The notion of the IU, the type of pitch contour, and the role of regulatory IUs will be applied in the following section in order to better understand the role of the cognitive verb collocations under consideration.

\section{Cognitive Verb Collocations and Their Role in Interaction}

One aspect of determining the different interactive functions of the collocations $I$ know, I think, and I guess involves determining how often each collocation is prosodically independent from the surrounding material - that is, how often it appears in an IU on its own. As mentioned above, the work presented by Chafe (1994) has discussed how items such as epistemic parentheticals and discourse markers, which frequently occur in their own IUs, have a regulatory role in discourse. 
Susan Buescher

A second variable that can provide evidence about the function of a collocation is related to where it occurs in a speaker's turn. In an ongoing discourse, collocations that occur at the beginning of a speaker's turn tend to be directly related to what the previous speaker has just said, and they perform a function of responding to and acknowledging the other speaker's turn, or serve to align the current speaker's turn with what has previously occurred in the discourse. Collocations that occur in the middle of a speaker's turn or at the end, just before they turn the floor over to another speaker, usually have a function of indicating what the speaker's stance is regarding what is being said within their own turn, and, as discussed by Kärkkäinen (2003), in these cases the collocation may have a larger, more global scope over the speaker's entire turn.

Both of these variables will now be taken into account in the discussion of each collocation, and it will be seen that they are largely dependent upon each other in the management of discourse.

\subsection{I know}

The collocation I know has a very unique function in comparison to the other collocations considered here, as it is frequently used by speakers not only as an epistemic stance-marker, but as a response token to acknowledge and agree with what another participant has just said. The distribution of the collocation in terms of prosodic independence and placement in a turn can be seen in Table 3 .

Table 3. Distribution of I know

\begin{tabular}{clllllll}
\hline & $\begin{array}{l}\text { prosodically } \\
\text { independent }\end{array}$ & \multicolumn{2}{l}{$\begin{array}{l}\text { not prosodically } \\
\text { independent }\end{array}$} & Total \\
\hline & $\mathbf{N}$ & $\mathbf{\%}$ & $\mathbf{N}$ & $\%$ & $\mathbf{N}$ & $\%$ \\
\hline backchannel & 38 & 44 & -- & -- & 38 & 23 \\
turn initial & 40 & 47 & 6 & 7 & 46 & 27 \\
turn medial & 6 & 7 & 75 & 93 & 81 & 49 \\
turn final & 2 & 2 & -- & -- & 2 & 1 \\
\hline \multicolumn{1}{c}{ Total } & 86 & 100 & 81 & 100 & 167 & 100 \\
\hline
\end{tabular}

As is indicated in Table 3, 86 of the 167 tokens of $I$ know (or 51\%) occur in an intonation unit on their own. Meanwhile, the combined total of the instances of $I$ know as a backchannel or in turn-initial position accounts for 84 of the 167 tokens (or 50\%). All of the 46 turn-initial tokens of $I$ know are also cases where the collocation occurred in its own IU, except for 6 tokens which consist of fixed phrases such as I know what you mean. Both of these characteristics are important aspects of the function of I know and demonstrate that speakers use this collocation as a regulatory IU, attending and managing interaction rather than contributing substantive content. Specifically, the fact that approximately half of the uses of the collocation I know occur in turn-initial position and also occur within their 


\section{The Use of Cognitive Verbs in American English}

own IU is strong supporting evidence that this collocation is used as a response token to an interlocutor's turn and indicates acknowledgement.

An example of I know as a backchannel can be seen in Kathy's reply to Nathan in example (1).

$$
\begin{array}{ll}
\text { Nathan: } & \text {.. I'm sitting here st- worrying about this one right here, } \\
\text { and there probably won't even be l- one like this on the test. } \\
\text { Kathy: } & \text {... I know. } \\
\text { Nathan: } & \text {.. There'll be a different one. } \quad \text { (Zero Equals Zero, 579-82) }
\end{array}
$$

In this example, Kathy uses $I$ know to both acknowledge and agree with what Nathan has just said, without giving any further indication of what it is she knows. When functioning as a backchannel, the collocation I know has moved furthest from its meaning of encoding speaker conviction and knowledge and has developed instead intersubjective meaning as an interactional device to attend to the speaker-hearer relationship during talk-in-interaction.

Related to its use as a backchannel for acknowledging another participant's contribution is the use of the collocation $I$ know as a response token in turn-initial position. An example of $I$ know in this context can be seen in example (2) below, where Marilyn responds to Roy's comment.

$$
\begin{array}{ll}
\text { Roy: } & \text { My but it's hot. } \\
\text { Marilyn: } & \text {... I know. } \\
& \text {.. In here you mean? } \\
\text { Roy: } & \text {.. Yes. }
\end{array}
$$

What is interesting about this example is that Marilyn acknowledges Roy's comment about the heat, and then after doing so asks for clarification. Therefore, it is clear that for Marilyn, the use of the collocation in this context does not refer to her actual knowledge of the topic, but rather acknowledgement of Roy's contribution. Acknowledgement and agreement are very important aspects of negotiating the floor during an ongoing discourse, and the use of $I \mathrm{know}$ in this environment shows that speakers have adapted this collocation to meet this interactional need.

\subsection{I think}

The collocation I think is used by speakers to assert their own opinions about a topic. Although I think may sometimes serve to hedge, or soften one's assertion, it does not always have a weakening effect and in fact seems to be the standard collocation used in American English conversation for introducing a speaker's own stance. The distribution of I think can be seen below in Table 4 . 
Susan Buescher

Table 4. Distribution of I think

\begin{tabular}{rllllll}
\hline & \multicolumn{2}{c}{$\begin{array}{c}\text { prosodically } \\
\text { independent }\end{array}$} & \multicolumn{2}{c}{$\begin{array}{c}\text { not prosodically } \\
\text { independent }\end{array}$} & Total \\
\hline & $\mathbf{N}$ & $\mathbf{\%}$ & $\mathbf{N}$ & $\mathbf{\%}$ & $\mathbf{N}$ & $\mathbf{\%}$ \\
\hline backchannel & 1 & 6 & -- & - & 1 & $<1$ \\
turn initial & 12 & 75 & 115 & 33 & 127 & 35 \\
turn medial & 2 & 13 & 223 & 64 & 225 & 62 \\
turn final & 1 & 6 & 11 & 3 & 12 & 3 \\
\hline \multicolumn{1}{c}{ Total } & 16 & 100 & 349 & 100 & 365 & 100 \\
\hline
\end{tabular}

As can be observed in Table 4, I think rarely occurs in its own IU; instead, 349 of the 365 instances (or 96\%) occur in an IU with other material. The fact that it occurs so often with other material, lacking prosodic independence, is an indication that it has a close relationship with the rest of the speaker's utterance. In addition to this, of the 16 cases involving I think in its own IU, 63\% occurred with a non-final intonation contour, indicating that the collocation is tightly connected to what follows it.

In 225 of the 365 occurrences of I think (or $62 \%$ ), the collocation is used in turn-medial position, where it often functions to assert an individual's opinion or stance toward the other material uttered in their turn. An instance of I think occurring in this position can be seen in example (3), where Lajuan indicates his opinion about why football players are attracted to him.

(3) Lajuan: .. And .. and what really gets me is th- \% that,

... (TSK) (H) $\underline{\text { I think }}$,

.. the reason I always attra $=$ cted,

like I attracted a lot of football players,

$(\mathrm{H})$ is people always .. got the impression .. I was gay $=$.

(He Knows, 1354-58)

Another example of $I$ think functioning to assert a speaker's stance can be seen in example (4), in which Ken shares his opinion about a slide show with Joanne. In this example, I think occurs twice, once in turn-initial position and once in turn-medial position, in both cases with the same function.

Joanne: But, so these slides $<\mathrm{X}$ should $\mathrm{X}>$ be real interesting.

Ken: $\quad$... Yeah.

I think it' 11 be real interesting,

I think it'll be a real,

(H) a good slide show.

(Deadly, 1-6) 


\section{The Use of Cognitive Verbs in American English}

In both examples (3) and (4), the speakers use the collocation I think to assert their stance on the following utterances. In example (4), Ken even uses the collocation I think twice, as if to make sure that his opinion on the slide show is noticed by Joanne. Furthermore, in neither of the examples is there any evidence that the use of I think serves to make the statement weaker. On the contrary, in (4), Ken uses the emphatic real to emphasize how interesting the slide show will be. These examples show that the specialized function of $I$ think is very different from either I know or I guess, as it used primarily by speakers to make their own assertions and positions known.

\subsection{I guess}

The collocation I guess has a specialized function of acting as an evidential type of marker (cf. Chafe 1986) and is used to mark a statement that is the result of drawing a conclusion based on evidence given, or is expressing knowledge that was obtained from another source. In order to encode the statement they are making as the result of some kind of circumstantial evidence, speakers commonly use the collocation I guess. This function is evidenced by the distribution of the collocation which is shown in Table 5.

Table 5. Distribution of I guess

\begin{tabular}{rllllll}
\hline & \multicolumn{2}{c}{$\begin{array}{c}\text { prosodically } \\
\text { independent }\end{array}$} & \multicolumn{2}{c}{$\begin{array}{c}\text { not prosodically } \\
\text { independent }\end{array}$} & Total \\
\hline & $\mathbf{N}$ & $\mathbf{\%}$ & $\mathbf{N}$ & $\mathbf{\%}$ & $\mathbf{N}$ & $\mathbf{\%}$ \\
\hline backchannel & -- & -- & -- & - & -- & -- \\
turn initial & 8 & 35 & 27 & 35 & 35 & 35 \\
turn medial & 10 & 43 & 45 & 58 & 55 & 55 \\
turn final & 5 & 22 & 5 & 7 & 10 & 10 \\
\hline \multicolumn{1}{r}{ Total } & 23 & 100 & 77 & 100 & 100 & 100 \\
\hline
\end{tabular}

Unlike I know, the collocation I guess never occurs as a backchannel, and only 23 of the 100 tokens (or 35\%) occur in prosodically independent IUs. The position that it occurs in most frequently is turn-medial, which accounts for $55 \%$ of the instances found in the corpus. The fact that it occurs so often in the midst of a speaker's own turn is evidence that $I$ guess is used to modify what the current speaker is saying, rather than as a response to what was said by the speaker of the preceding turn. This is demonstrated in example (5), in which Seth makes a statement about his brother's research.

$$
\begin{aligned}
& \text { Seth: } \quad \text {... Yeah, } \\
& \text { my brother is uh, } \\
& \text {... teaches linguistics, } \\
& \text { and } \underline{\text { I guess }} \text { he's doing this study, }
\end{aligned}
$$


Susan Buescher

$$
\begin{array}{ll}
\text { Larry: } & \begin{array}{l}
\mathrm{Oh}= \\
\end{array} \\
& <\mathrm{X} \text { okay } \mathrm{X}> \\
\text { Seth: } & \ldots \text { and they just want ... business conversations. } \\
\text { Larry: } & \quad \ldots \text { alright. }
\end{array}
$$

In this example, Seth has clearly been informed about his brother's research, and can therefore be said to have some knowledge of the subject. Nevertheless, when describing the project to someone else, he uses the collocation I guess to distance himself from what is being said and indicate that he is not the one responsible and may therefore not know all of the details. His choice to use I guess in this context is directly related to the fact that he is threatening Larry's face in asking him to be recorded for the project. Because he risks receiving a dispreferred response with this request, the distance provided by the evidential marker helps to attend to this face-threatening situation.

Further evidence supporting the claim that I guess is used as an evidential marker is its frequent co-occurrence with other evidentials and markers of hearsay. Example (6) below demonstrates the use of I guess in co-occurrence with the words apparently and they say, which also serve to imply that the statement is based upon some kind of hearsay. In this example, Frank is relating to some friends the news of another friend's recent death while in Africa.

Frank: $\quad(\mathrm{H})$ But apparently it was either a heart attack or an aneurysm, Ron: $\quad H m$.

Frank: and they suspect an aneurysm, it was extremely quick,

I guess. $\quad$ (Doesn't Work in This Household, 870-74)

Frank makes use of both the collocation I guess and the words apparently and they say to distance himself from the statements he is making regarding this event. The discourse context which gives rise to this situation is the discussion of a death which occurred overseas and is therefore somewhat unknown. In this context, Frank feels the need to remain partially removed from the information he is sharing with his friends. Furthermore, by placing I guess at the end of his turn Frank ensures that the collocation has scope over everything he has just said.

The use of I guess with this evidential meaning is a result of the interactional need between discourse participants for marking secondhand information and maintaining distance. Although English lacks a grammatical evidential system, speakers have adapted the collocation I guess to meet this interactional need. The fact that guess is the verb with the most highly restricted distribution and is used $95 \%$ of the time in conversational discourse in the specific collocation I guess, as was observed earlier in Table 2, is further evidence to support the claim that this collocation has developed the discourse function of an evidential marker. 


\section{The Use of Cognitive Verbs in American English}

\section{Conclusion}

This paper has examined the three semantically and syntactically similar collocations I know, I think, and I guess. Through consideration of prosodic characteristics and placement within the turn, it has been shown that in fact these three collocations serve very different interactional roles. I know is used primarily to attend to the speaker-hearer relationship, showing acknowledgement and agreement of what has been said in a prior turn, as reflected in its frequent use in an IU on its own as a backchannel or at the beginning of a turn. The collocation I think is used to present a speaker's stance toward their utterance. The tight connection between I think and the other utterances in a speaker's turn is reflected in the fact that it occurs almost exclusively in an IU with other material. I guess occurs most often in turn-medial position, and is used mainly as an evidential device encoding a speaker's statement as based on hearsay and secondhand knowledge. This study demonstrates that the specialization of the collocations is a direct result of how they are used by conversationalists to accomplish the work they have during talkin-interaction.

Transcription Conventions (Du Bois et al. 1993)

$\begin{array}{llll} & \text { final intonation contour } & \ldots & \text { medium pause }(\sim 0.7 \mathrm{sec}) \\ , & \text { continuing intonation contour } & . . & \text { short pause }(<0.7 \mathrm{sec} .) \\ ? & \text { appealing intonation contour } & \% & \text { glottal stop } \\ -- & \text { truncated intonation contour } & = & \text { lengthened syllable } \\ (\mathrm{TSK}) & \text { alveolar click } & (\mathrm{H}) & \text { audible inhalation } \\ <\mathrm{XX}> & \text { uncertain hearing } & (\mathrm{Hx}) & \text { audible exhalation }\end{array}$

\section{References}

Chafe, Wallace. 1986. Evidentiality in English Conversation and Academic Writing. In W. Chafe and J. Nichols, eds., Evidentiality: The Linguistic Encoding of Epistemology, 261-272. Norwood, NJ: Ablex Publishing Corporation.

Chafe, Wallace. 1994. Discourse, Consciousness and Time: The Flow and Displacement of Conscious Experience in Speaking and Writing. Chicago: University of Chicago Press.

Diessel, Holger, and Michael Tomasello. 2001. The Acquisition of Finite Complement Clauses in English: A Corpus-Based Analysis. Cognitive Linguistics 12(2):97-141.

Du Bois, John W. 2000. Santa Barbara Corpus of Spoken American English, Part I [3 CD-ROMs]. Philadelphia: Linguistic Data Consortium, University of Pennsylvania.

Du Bois, John W., Wallace L. Chafe, Charles Meyer, Sandra A. Thompson, and Nii Martev. 2003. Santa Barbara Corpus of Spoken American English, Part II 
Susan Buescher

[1 DVD]. Philadelphia: Linguistic Data Consortium, University of Pennsylvania.

Du Bois, John W., and Robert Englebretson. 2004. Santa Barbara Corpus of Spoken American English, Part III [1 DVD]. Philadelphia: Linguistic Data Consortium, University of Pennsylvania.

Du Bois, John W., Stephan Schuetze-Coburn, Susanna Cumming, and Danae Paolino. 1993. Outline of Discourse Transcription. In Jane Edwards and Martin Lampert, eds., Talking Data: Transcription and Coding in Discourse, 45-89. Hillsdale, NJ: Lawrence Erlbaum Associates.

Kärkkäinen, Elise. 2003. Epistemic Stance in English Conversation: A Description of Its Interactional Functions with a Focus on I think. Amsterdam: John Benjamins.

Scheibman, Joanne. 2000. I dunno: A Usage-Based Account of the Phonological Reduction of don't in American English Conversation. Journal of Pragmatics 32(1):105-124.

Tao, Hongyin. 2003. A Usage-Based Approach to Argument Structure: remember and forget in Spoken English. International Journal of Corpus Linguistics $8(1): 75-95$.

Tao, Hongyin. 2001. Discovering the Usual with Corpora: The Case of remember. In Rita C. Simpson and John M. Swales, eds., Corpus Linguistics in North America, 116-144. Ann Arbor: University of Michigan Press.

Thompson, Sandra A. 2002. 'Object Complements' and Conversation: Towards a Realistic Account. Studies in Language 26(1):125-163.

Thompson, Sandra A., and Anthony Mulac. 1991a. The Discourse Conditions for the Use of the Complementizer 'that' in Conversational English. Journal of Pragmatics 15:237-251.

Thompson, Sandra A., and Anthony Mulac. 1991b. A Quantitative Perspective on the Grammaticization of Epistemic Parentheticals in English. In Elizabeth Closs Traugott and Bernd Heine, eds., Approaches to Grammaticalization, Vol. 1, 313-329. Amsterdam: John Benjamins.

Travis, Catherine E. In press. Subjetivización de construcciones: Los verbos 'cognitivos' en el español conversacional. Serie Memorias del VIII Encuentro Internacional de Lingüística en el Noroeste.

Susan Buescher

University of New Mexico

Department of Linguistics

Humanities Building, Room 526

Albuquerque, NM 87131-1196

suesmb@unm.edu 